\title{
Giant Intramural Hematoma of the Colon in Acquired Factor VIII Inhibitor
}

\author{
Hematoma Intramural Gigante do Colon em Doente \\ com Inibidor do Factor VIII Adquirido
}

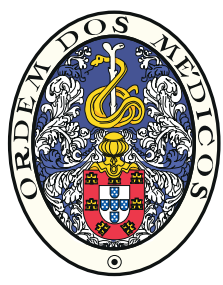

\begin{abstract}
Joana FIGUEIREDO ${ }^{1}$, Nuno BORGES ${ }^{1}$, José PASCOALINHO ${ }^{1}$, Ricardo MATOS ${ }^{1}$
Acta Med Port 2019 Sep;32(9):614-617 - https://doi.org/10.20344/amp.8519

ABSTRACT

Intramural hematoma of the colon is very rare, particularly when associated with the development of autoantibodies against factor VIII. We report a case of a 66-year-old man with abdominal pain, hematochezia and clots in the left colon, without any radiologic signs of active bleeding or bowel occlusion or analytical changes in routine coagulation screening, but with positive autoantibodies against factor VIII. The clinical instability prompted surgical exploration. An intramural hematoma of the left colon was found, and a left colectomy was performed. The patient was treated with hemoderivatives and corticosteroids with clinical improvement. The diagnosis of spontaneous intramural hematoma might be a challenge, particularly in the absence of clinical suspicion. An early recognition is essential for a positive outcome. This case highlights a rare cause of bleeding and intestinal obstruction, but also the difficulty and relevance of establishing a clinical diagnosis when diagnostic tests are not completely informative.
\end{abstract}

Keywords: Colon; Hematoma; Hemophilia A; Factor VIII

\section{RESUMO}

O hematoma intramural do colon é uma entidade rara, especialmente quando associada ao desenvolvimento de anticorpos anti fator VIII. Apresentamos um homem, 66 anos, com dor abdominal, hematoquézias e presença de coágulos no cólon esquerdo, radiologicamente sem sinais de hemorragia ativa ou oclusão intestinal e sem alterações analíticas nas provas de coagulação, mas com presença de anticorpos contra o factor VIII. Por agravamento e instabilidade clínica foi submetido a laparotomia exploradora, tendo-se verificado a presença de hematoma intramural do colon esquerdo, pelo que se procedeu a hemicolectomia esquerda. Foi medicado com hemoderivados e corticoides com evolução clínica favorável. O diagnóstico do hematoma intramural espontâneo pode ser um desafio, principalmente na ausência de suspeita clínica. O seu reconhecimento precoce é essencial para uma evolução favorável. Este caso releva uma causa rara de hemorragia e oclusão intestinal, bem como a dificuldade e importância do diagnóstico clínico na ausência de exames complementares elucidativos.

Palavras-chave: Hematoma Colon; Hematoma; Hemofilia A; Factor VIII

\section{INTRODUCTION}

Acquired hemophilia is a rare bleeding disorder caused by the development of autoantibodies against plasma coagulation factors, most frequently factor VIII. ${ }^{1}$

Normal hemostasis requires at least $25 \%$ of factor VIII activity, which is decreased in patients with acquired inhibitors against factor VIII. ${ }^{2}$

Standard coagulation studies can be normal, including thrombin and prothrombin times (PT) as well as platelet count and function. The typical findings of acquired hemophilia are a prolonged activated partial thromboplastin time (aPTT) and a low factor VIII level, with the latter not being routinely requested. ${ }^{1}$

Treatment priorities are to stop the bleeding and to eradicate factor VIII autoantibodies. Immunosuppressive treatment with corticosteroids and cytotoxic drugs alone or in combination is regarded as the appropriate treatment. ${ }^{3}$

Intramural colonic hematomas are rather uncommon ${ }^{4}$ and are mostly characterized by abdominal pain, rectal bleeding and bowel obstruction depending on the size and location of the hematoma. The most frequent causes of intramural bowel hematoma are abdominal trauma, anticoagulant therapy, blood dyscrasias or iatrogenesis. ${ }^{5}$
The aim of this paper is to highlight the occurrence of acute abdominal obstruction due to spontaneous intramural colonic hematoma resulting from the unusual cause of acquired hemophilia.

\section{CASE REPORT}

A 66-year-old man, diagnosed four years before with Crohn disease affecting the right colon, presented to the emergency department complaining in the last day of 14 episodes of diarrheal stools with hematochezia and abdominal pain in the left lower quadrant, without previous story of colorectal trauma, as well as signs of colonic infection. Blood analysis revealed a normochromic normocytic anemia [haemoglobin $8.9 \mathrm{~g} / \mathrm{dL}(13.5-17.5)$ ] normal platelet and white blood cell counts $\left[176 \times 10^{\wedge} \mathrm{g} / \mathrm{L}\right.$ platelets $(150-450 \times$ $\left.10^{\wedge} \mathrm{g} / \mathrm{L}\right), 10.1 \times 10^{\wedge} \mathrm{g} / \mathrm{L}$ WBC $\left.\left(4.5-11.0 \times 10^{\wedge} \mathrm{g} / \mathrm{L}\right)\right]$ and $a$ prolonged aPTT [49.1 s $(25.1-36.5 \mathrm{~s})]$ with normal PT and international normalized ratio (INR). Colonoscopy showed a clot $50 \mathrm{~cm}$ from the anal verge which occluded the lumen. The patient received transfusion of three units of packed red blood cells (PRBCs), one gram of fibrinogen and three units of plasma in the emergency room. After being admitted to the Gastroenterology unit, he presented clinical worsening,

1. Department of General Surgery. Centro Hospitalar Universitário de Lisboa Central. Lisboa. Portugal.

$\triangle$ Autor correspondente: Joana Figueiredo. joanabfigueiredo@gmail.com

Recebido: 28 de novembro de 2016 - Aceite: 24 de setembro de 2018 | Copyright @ Ordem dos Médicos 2019 
with abdominal distension, generalized pain and persistent bleeding. Abdominal computerized tomography (CT) did not show signs of active haemorrhage or wall thickening. Reordered coagulation analysis indicated prolonged PT [14 seconds (9.4 - $12.5 \mathrm{~s})$ ], and aPTT [48.1 seconds $(25.1-36.5 \mathrm{~s})]$, as well as decreased activity of factor VIII [30.70\% (50\% - 150\%)], increased factor VIII inhibitor titer [2.01 U Bethesda (negative < 0.5)], and increased functional Von Willebrand Factor [284.6\% (48.8\% - 163.4\%)]. Since gastrointestinal bleeding persisted, the haemoglobin level continued to fall and the patient became unstable, and was then transfused with one PRBCs and three plasma units and admitted to the intensive care unit.

Colonoscopy was repeated, revealing at the same level of the previous clot a violaceous mucosa with necrosis and segments of destruction over around $20 \mathrm{~cm}$. Surgical exploration was decided. After administration of $3000 \mathrm{U}$ of factor VIII and four PRBCs, exploratory laparotomy was performed and found the left colon filled with an intramural hematoma from the sigmoid to the splenic flexure, causing distension of the proximal colon (Figs. 1-3). A left colectomy was done with mechanical closure of the distal stump and

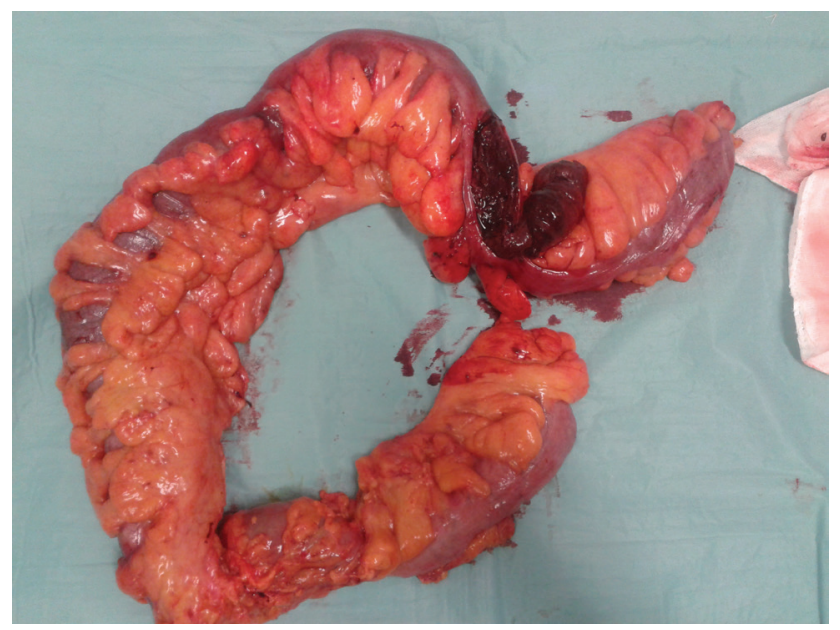

Figure 1 - Specimen of resected left colon evidencing distension of the bowel

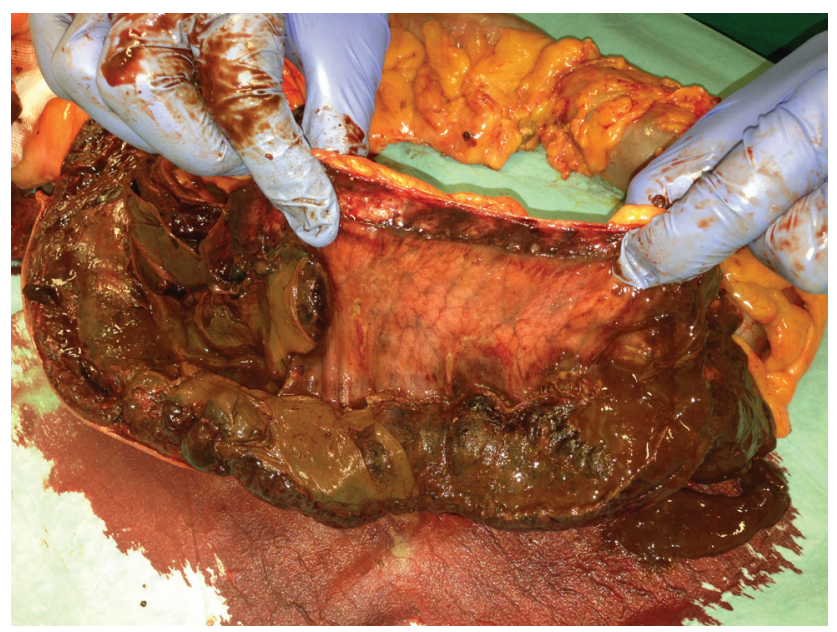

Figure 3 - Detail of intramural colon hematoma terminal colostomy. Histopathology confirmed an extended submucosal hematoma with necrosis of mucosa and without signs of Crohn disease (Fig. 4). On the first postoperative day, the patient received $3000 \mathrm{U}$ of factor VIII and started prednisolone (120 mg/day). He also received three more PRBCs on the third postoperative day and $238000 \mathrm{U}$ of anti-inhibitor coagulant complex during the 17 days following the postoperative day. The eradication of factor VIII inhibitors three weeks after surgery, allowed the start of corticosteroid tapering. A deep incisional surgical site infection was detected and treated with piperacillin-tazobactam and dressings. The patient was discharged on the $26^{\text {th }}$ day after surgery and referred to the immunohemotherapy outpatient clinic. Corticosteroid tapering was completed four months after surgery, with normal activity of factor VIII and negative factor VIII inhibitor titre. Five months later, the patient underwent endoscopic evaluation, with intestinal mucosa without changes, and intestinal transit was reestablished

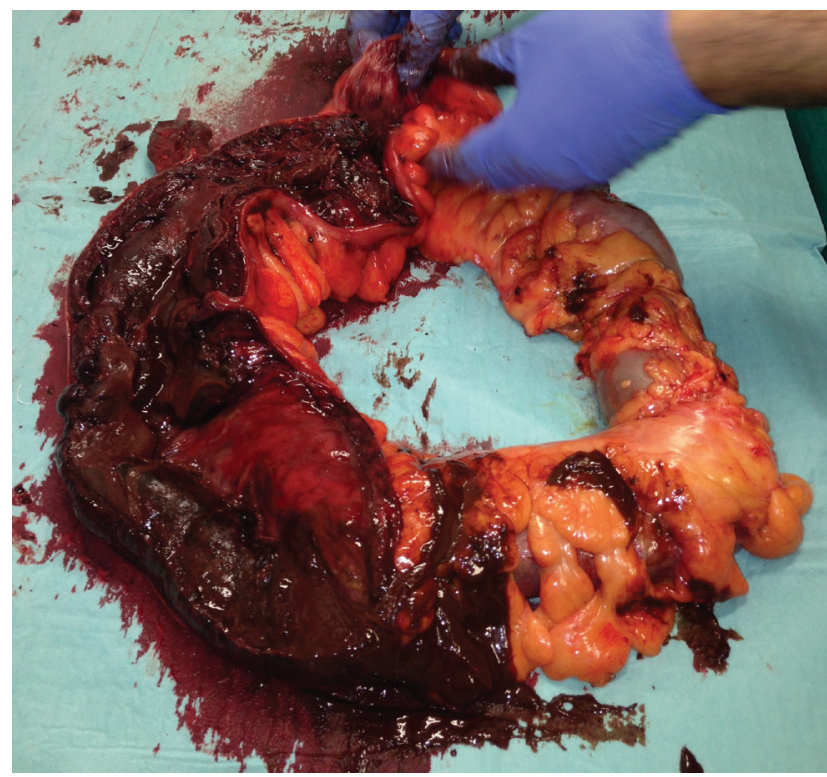

Figure 2 - Fresh section of the resected specimen showing hematoma

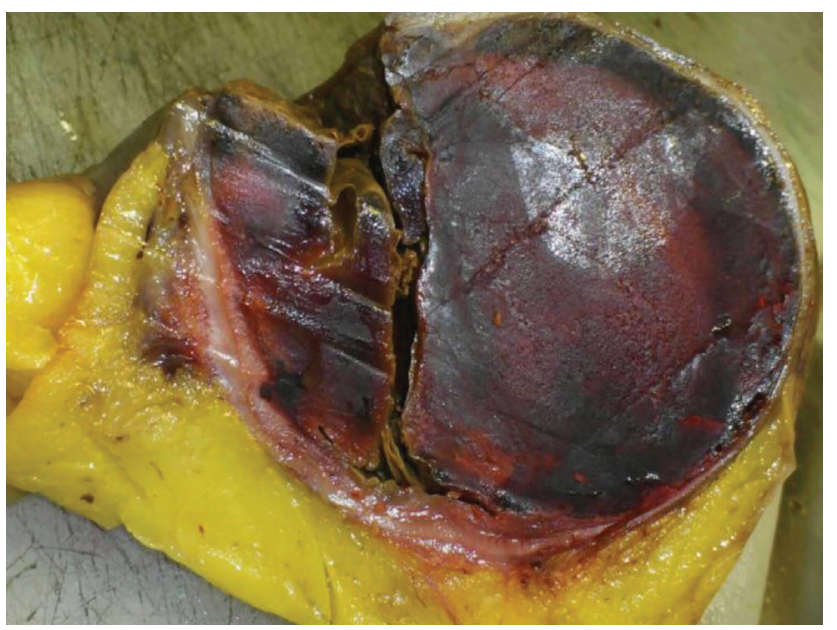

Figure 4 - Preserved macroscopic cross-section of resected left colon showing large hematoma narrowing the colic lumen 
with mechanical colonic anastomosis. The postoperative period was uneventful, and the patient was discharged on DISCUSSION

Intramural hematoma of the colon is a rare event that can be secondary or 'spontaneous'. ${ }^{6}$ The haemorrhage is usually located in the submucosal layer of the bowel due to the presence of more vascular structures. ${ }^{7}$ Haemorrhagic ascites can be present and is usually related to leakage of blood from an engorged, thickened and inflamed bowel wall with submucosal bleeding extending into all layers. ${ }^{8}$

It is believed that the progression of the symptoms is due to the establishment of an intramural osmotic gradient and the presence of the hematoma, leading to an expansion of the intestinal wall.

The diagnosis of intramural hematoma of the colon is a clinical challenge, because signs and symptoms are not specific $^{6}$ and clinical suspicion is crucial.

The clinical presentation depends on the location of the hematoma, and symptoms of either high or low bowel obstruction may predominate. ${ }^{6,9}$ Abdominal pain is present in almost all cases, being either diffuse or predominantly located in the site of the hematoma. Signs of peritoneal irritation are suggestive of complications such as necrosis, perforation or hemoperitoneum. Digestive bleeding occurs in about $40 \%$ of the cases. ${ }^{9}$

Abdominal CT may be important to the diagnosis, with suggestive images of circumferential wall thickening, intramural hyperdensity, luminal narrowing, intestinal obstruction, and hyperdense ascites. ${ }^{4,8}$ However there are no pathognomonic CT changes ${ }^{4}$ and plain abdominal $\mathrm{x}$-ray films reveal only typical patterns of colic obstruction if present.

Colonoscopy may be useful to show hematoma signs like "blue and roundish formations" in the submucosal layer. ${ }^{6}$

In this case, the analytical results were key for the diagnosis of acquired haemophilia and the diagnosis of intramural hematoma was neither evident in the CT scan nor in the colonoscopy.

Although rare, massive gastrointestinal tract bleeding can occur as a complication of Crohn's disease and can be particularly difficult to control. It is also known that bleeding is more frequent among patients with colonic involvement, especially of the descending colon and rectum. ${ }^{10}$ Since the patient had a previous diagnosis of Crohn's disease, we strongly considered it as a cause for the haemorrhage, even though the latest colonoscopy of the patient, one year before, showed just three superficial ulcers in the right colon. Nevertheless, diagnostic procedures that are used in patients with lower gastrointestinal bleeding are similar in patients with or without inflammatory bowel disease. ${ }^{10}$

The decision for surgical intervention was determined by the persistent haemorrhage, signs of bowel obstruction and the clinical instability of the patient.

The appropriate pharmacological treatment of patients with acquired haemophilia depends essentially on the natural history of any concomitant pathology and the clinical presentation of coagulopathy. A conservative treatment with corticosteroids is usually recommended for acquired inhibitor haemophilia in the first instance.

The differential diagnosis of a haemorrhagic disorder with normal baseline coagulation studies is limited to clinical suspicion, and a failure to recognize an uncommon acquired coagulation disorder can have serious consequences. ${ }^{3}$

For the treatment of colonic haematoma, surgical treatment is suggested for those patients with a doubtful diagnosis or those who exhibit a deteriorating condition, an irreversible intestinal obstruction, signs of bowel necrosis or peritonitis. ${ }^{6}$

The surgical treatment with resection of the intestinal segment with hematoma is the gold standard therapy. Very few cases have been treated by endoscopic evacuation with a good outcome, and only when mucosal perforation was absent. ${ }^{6,7}$

A prompt and early recognition of nontraumatic, spontaneous, large-bowel intramural hematoma, and early involvement of surgical care is crucial for a positive outcome.

Rare coagulation disorders, like acquired inhibitor haemophilia presented in this case, are important to consider in the differential diagnosis for a colonic haemorrhage or obstruction of unknown cause.

\section{CONCLUSION}

The present case reports an atypical cause of low gastrointestinal haemorrhage, associated with the presence of coagulopathy due to an acquired inhibitor of factor VIII. The diagnosis of intramural hematoma implies a high level of clinical suspicion due to its non-specific clinical presentation. The delay in diagnosis leads to a delay in effective treatment, with poor outcome and increased associated costs.

\section{CONFLICT OF INTEREST}

The authors certify that they have NO affiliations with or involvement in any organization or entity with any financial interest (such as honoraria; educational grants; participation in speakers' bureaus; membership, employment, consultancies, stock ownership, or other equity interest; and expert testimony or patent-licensing arrangements), or non-financial interest (such as personal or professional relationships, affiliations, knowledge or beliefs) in the subject matter or materials discussed in this manuscript.

\section{PROTECTION OF HUMANS AND ANIMALS}

The authors declare that the procedures were followed according to the regulations established by the Clinical Research and Ethics Committee and to the Helsinki Declaration of the World Medical Association.

\section{DATA CONFIDENTIALITY}

The authors declare having followed the protocols in use at their working center regarding patients' data publication. 


\section{INFORMED CONSENT}

Obtained.

\section{CONFLICTS OF INTEREST}

All authors report no conflict of interest.

\section{References}

1. Giangrande P. Acquired hemophilia. Treatment of hemophilia [serial online]. 2012; November(38). [accessed 2015 Dec 20]. Available from: http://www1.wfh.org/publications/files/pdf-1186.pdf.

2. Factor VIII assay: reference range, interpretation, collection and panels [Medscape]. Devkota: St Louis University School of Medicine; 2016.

3. Gregory TF, Cooper B. Case report of an acquired factor XIII inhibitor: diagnosis and management. Proc. 2006;19:221-3.

4. Lobo L, Koudki R, Kishan Prasad HL, Shetty B. Colon obstruction due to an anticoagulant induced intramural haematoma; a rare case report. J Clin Diagn Res. 2013;7:739-41.

5. Chin C, Yeh C, Kuo Y, Huang W, Yeh C, Wang J. Colon obstruction due to anticoagulant — induced intramural hematoma. J Soc Colon Rectal Surgeon. 2007;18:111-5.

\section{FUNDING SOURCES}

The authors declare that there were no external sources of study for the performance of this article.

6. De Santis G, Sista F, Giuliani A, Leardi S. Idiopathic intramural hematoma of sigmoid colon. Ann Ital Chir. 2011;82:395-7.

7. Yin W, Gueng M, Huang S, Chen H, Chang T. Acute colonic intramural hematoma due to blunt abdominal trauma. Int Surg. 2000;85:51-4.

8. Altinkaya N, Parlakgümüs A, Demir S, Alkann Ö, Yildirim T. Small bowel obstruction caused by intramural hematoma secondary to warfarin therapy: a report of two cases. Turk J Gastroenterol. 2011;22:199-202.

9. Sorbello MP, Utiyama EM, Parreira JG, Birolini D, Rasslan S. Spontaneous intramural small bowel hematoma induced by anticoagulant therapy: review and case report. Clinics. 2007;62:785-90.

10. Harb WJ. Crohn's disease of the colon, rectum, and anus. Surg Clin N Am. 2015;95:1195-210. 